\title{
PADRÃO DOS INVESTIMENTOS BRITÂNICOS E A MODERNIZAÇÃO CONSERVADORA NA ECONOMIA BAIANA OITOCENTISTA
}

\section{STANDARD OF THE BRITISH INVESTMENTS AND THE MODERNIZATION CONSERVATIVE IN BAHIAN ECONOMY OITOCENTISTA}

Marcos Guedes Vaz Sampaio*

\begin{abstract}
Resumo: No decorrer da segunda metade do século XIX os investimentos britânicos se tornaram mais expressivos na economia baiana. Percebe-se, no entanto, que foram direcionados, prioritariamente, para os setores relacionados ao desenvolvimento da infra-estrutura destacando-se os transportes. A ampliação dessas inversões promoveu uma melhoria nas relações mercantis, porém como não foram voltadas para a transformação da estrutura produtiva vigente, contribuíram para o recrudescimento do modelo primário-exportador. Em outras palavras, proporcionaram uma modernização da infra-estrutura, contudo conservando o modelo arcaico que até então existia na Província da Bahia.
\end{abstract}

Palavras-chave: Inglaterra; Bahia; Investimentos; Infra-estrutura; Dependência.

Abstract: In elapsing of the second half of century XIX the British investments if had become more expressive in the Bahia's economy. It is perceived, however, that they had been directed, with priority, for the sectors related to the development of the infrastructure in focus the transports. The magnifying of these inversions promoted an improvement in the mercantile relations, however as they had not been come back toward the transformation of the effective productive structure, they had contributed for the new outbreak of the model elementary primary-exporter. In other words, they had provided a modernization of the infrastructure, however conserving the archaic model that until then existed in the Province of the Bahia.

Key words: England; Bahia; Investments; Infrastructure; Dependency.

\section{Introdução}

O desenvolvimento do processo de dependência econômica latino-americana durante 0 século XIX aconteceu a partir da desagregação do sistema colonial, quando as principais nações européias passaram a dominar o seu comércio. As relações até então existentes envolviam os espectros político e econômico, e esses estavam intimamente relacionados por meio da interligação metrópole-colônia. Um panorama de estreita dependência, principalmente configurada pela ausência de emancipação política dos territórios da América Latina.

A ruptura do sistema colonial inaugurou um novo cenário, no qual os processos de independência política aventaram outras possibilidades de intercâmbios comerciais, assim como sua expansão. Os entes constitutivos desse quadro de relações mercantis experimentaram uma ampliação, coordenada pelas economias centrais, destacando-se a Inglaterra, por seu papel de vanguarda na era industrial e sua posição hegemônica na economia-mundo. Os interesses, no entanto, eram divergentes das antigas metrópoles (Portugal e Espanha), restringindo-se, tão somente à expansão capitalista através do recrudescimento do comércio com as novas nações independentes do ponto de vista político. Fernandes (1981, p. 14-15) aponta:

\footnotetext{
* Doutor em História Econômica (USP) e professor adjunto do Instituto de Humanidades, Artes e Ciências Milton Santos (IHAC/UFBA). E-mail: mgvsampaio@hotmail.com / marcos.sampaio@ufba.br.
} 
As nações européias, que conquistaram o controle dos negócios de exportação e de importação na América Latina (a Inglaterra em particular), estavam inicialmente mais interessadas no comércio que na produção local. Durante quase quatro ou cinco décadas - do fim do século XVIII até as primeiras três ou quatro do século XIX - esses países ocuparam o vácuo econômico deixado pela desagregação do antigo sistema colonial, ao invés de exercerem o papel de um poder 'imperial'.

Essa nova ambiência traduzida na dominação do comércio das economias latino-americanas pelas nações européias contribuiu para o fortalecimento e a manutenção do modelo econômico monocultor, produtor de bens primários e de viés exportacionista ${ }^{1}$. A especialização produtiva dos países da América Latina na exportação de determinadas mercadorias ligadas ao setor agrícola, pecuário e extrativista levou a um processo exacerbado de concentração de capitais nas mãos de uma elite pertencente a esse segmento. 0 crescimento da riqueza acumulada por essa elite se reverteu nos crescentes registros de importação de bens manufaturados e artigos de luxo, tendo sido apresentado por Almeida (1951) como uma das principais causas dos constantes déficits da balança comercial baiana no decurso do século XIX. Os hábitos suntuosos das elites das economias latino-americanas também foram apontados por Sunkel (1973, p. 26):

O fato de um país especializar-se na exportação de um determinado produto indica que ele alcançou boa capacidade de competição e produtividade neste setor; isto faz com que pareça conveniente obter no exterior os bens de consumo manufaturados destinados a satisfazer a demanda dos grupos sociais de altas rendas.

A manutenção do modelo primário-exportador de natureza dependentista encontrou na elite nativa uma fiel colaboradora. A aliança entre capitalistas estrangeiros e elite local ocorreu tanto sob o aspecto econômico, quanto político. Essas relações extrapolavam a esfera do fausto consumo doméstico, se imiscuindo pela área administrativa e financeira dos empreendimentos que se instalavam em terras latino-americanas. A tendência concentradora dos capitais que aportavam por aqui tinha origem prioritariamente britânica, mas também belga, francesa, alemã e até norteamericana (CASTRO, 1978, p. 83), fortemente relacionados aos agentes econômicos internos. Esses capitais externos foram investidos em atividades de interesse dos capitalistas das economias centrais, normalmente vinculados a setores infra-estruturais, proporcionando sua modernização, porém sem reflexos no sentido de transformar a estrutura produtiva vigente. Santos $(2000$, p. 74$)$ destacou:

[...] o capital estrangeiro, que teve um papel muito importante na criação do setor exportador de vários países, por se tornarem verdadeiros 'enclaves externos', que não

\footnotetext{
${ }^{1}$ Aqui entendido como modelo econômico dominante nas economias latino-americanas do período oitocentista. 0 presente artigo não desconsidera os avanços da produção historiográfica contemporânea que redimensiona o papel do mercado interno nessas nações, principalmente a brasileira. Apenas reitera o caráter principal desse modelo, representado pelo vetor dinâmico de exportação de bens primários e centrado nos latifúndios monocultores como seus elementos principais de sustentação.
} 
produziam qualquer efeito sobre o conjunto das economias nacionais. Os investimentos nos setores exportadores não criaram 'economias externas'.

Gunnar Myrdal (1968, p. 88) apontou a questão tecnológica como fator de perpetuação do modelo dependentista: "[...] qualquer progresso tecnológico, na sua produção de exportação, tende a transferir as vantagens dos custos mais baixos de produção para os países importadores". Os investimentos em progressos técnicos situados nos segmentos de apoio ao modelo primárioexportador representavam redução de custos, principalmente com transportes, para as oligarquias rurais, otimizando sua competitividade no mercado mundial e redução dos preços dos bens primários importados pelas economias centrais, contribuindo para melhorar o desempenho de suas balanças comerciais.

Os capitais estrangeiros e a tecnologia não podem ser considerados, no entanto, como fatores exclusivamente negativos no processo de desenvolvimento das economias periféricas. Benefícios como o advento das companhias de navegação a vapor, as ferrovias, a iluminação a gás, o telégrafo, dentre outros, contribuíram para modernizar e criar condições melhores para 0 desenvolvimento econômico. O ponto principal é que estas melhorias serviram apenas para aperfeiçoar o sistema vigente, promovendo sua modernização, sem, contudo, colaborar na transformação do seu caráter de modelo primário-exportador.

As elites locais estavam interessadas no desenvolvimento do setor agrícola, defendendo seus interesses, discordando de qualquer política de industrialização interna, como evidenciou Nícia Vilela Luz². As economias centrais, por outro lado, não tinham interesse em realizar investimentos que contribuíssem para promover a transformação na estrutura do modelo dependentista, uma vez que isto modificaria a inserção desses países na divisão internacional do trabalho, como Castro (1978, p. 21) ressaltou:

É bem sabido que o objetivo último da política do livre comércio era solidificar uma divisão internacional do trabalho, na qual o "resto do mundo" proviria os mercados britânicos de alimentos e matérias-primas baratos, enquanto a Inglaterra se especializaria na produção manufatureira.

A manutenção do modelo interessava tanto aos investidores ingleses por meio dos lucros que auferiam em razão das inversões realizadas nas economias periféricas, quanto às elites locais, através da melhoria da competitividade internacional de suas mercadorias. 0 centro dinâmico dessas economias voltado para fora reforçava o caráter concentrador e dependente do modelo primário-exportador. A chamada modernização conservadora se revelava nos elementos

\footnotetext{
2 LUZ, Nícia Villela. A Luta Pela Industrialização do Brasil (1808-1930). São Paulo: Difusão Européia do Livro, 1961.
} 
transformadores adjacentes das sociedades tradicionais, mantendo 0 arcaísmo das estruturas socioeconômicas ainda ligadas ao passado colonial.

\section{Modernização conservadora na economia brasileira oitocentista}

A expressão "modernização conservadora", cunhada pelo historiador inglês Barrington Moore Jr. (1983), originariamente remete ao processo de transformação da estrutura produtiva das sociedades alemã e japonesa no decurso do século XIX que aliou um projeto modernizante do ponto de vista econômico a um ambiente político de forte conservadorismo. A aparente contradição resultante de uma leitura preliminar dessa expressão revela a ambigüidade de se interpretar um determinado momento, enquanto ente constitutivo do arcabouço histórico, por meio da transmudação dos elementos identificados com a modernidade e seu contraponto relacionado ao arcaísmo.

As estruturas identificadas com os arquétipos da modernidade tornam-se contraditórias se interpretadas dentro de um contexto de forte cunho conservador. Isso se revelou nos estudos de Barrington Moore Jr. (1983) e foi traduzido pelo autor com propriedade quando estabeleceu essa relação nos cenários político e econômico alemães e japoneses. A ideia de conservadorismo, naturalmente remete à manutenção do status quo e, por conseguinte, não se traduz em modificações da estrutura vigente, salvo se essas mudanças estão relacionadas a um aperfeiçoamento do modelo existente, buscando uma perpetuação de sua organização estrutural básica. Nos casos estudados por Moore Jr. (1983), a modernização se referia aos aspectos econômicos e, o conservadorismo, ao ambiente político.

A análise das relações econômicas entre o Brasil e a Inglaterra, no decorrer do século XIX permite identificar elementos transformadores da estrutura produtiva, por meio de sua modernização, associada ao conservadorismo político e econômico, este no sentido estrito às modificações no cenário subsidiário ao desenvolvimento das estruturas produtivas. Embora, reconhecidamente, o panorama político fosse conservador, os aspectos de natureza econômica se mostravam expressivos o suficiente para restringir a investigação a esse campo. Os interesses da classe dominante, ligadas ao setor agrícola, convergiam com os interesses britânicos, associandose a eles. A modernização do setor agrícola e a manutenção da estrutura social e econômica refletiam os objetivos das oligarquias brasileiras. Os ingleses, por outro lado, buscavam ampliar suas inversões para além dos segmentos primários da economia, utilizando-se das vantagens do seu papel vanguardista no cenário econômico mundial, no entanto, sem abdicar da estratégia de consolidação da divisão internacional do trabalho. Dito de outro modo, sem criar possibilidades de inserção de algum país periférico no eixo de nações industrializadas. Moore Jr. (1983, p. 427) traz uma reflexão neste sentido ao analisar o caso do Japão: 
Uma classe superior proprietária pode, como no caso do Japão, manter intacta a sociedade camponesa pré-existente, introduzindo apenas as alterações suficientes, na sociedade rural, para garantir que os camponeses produzam um excedente suficiente, de que se possa apropriar e vender com lucro. Ou então, a classe superior proprietária poderá criar sistemas sociais inteiramente novos, dentro do estilo da escravatura das plantações.

O afluxo de capitais britânicos para o Brasil e, no caso particular desse estudo, especificamente para a Bahia, foi direcionado prioritariamente para os setores relacionados à infraestrutura econômica. Enquanto a Inglaterra vivenciava as transformações oriundas da Revolução Industrial e experimentava avanços tecnológicos em diversos ramos de sua estruturação produtiva, restringia a exportação dos bens de capital ou de tecnologia diretamente ligados aos setores considerados estratégicos. O segmento têxtil, precípuo da era industrial e vetor dinâmico da transmudação desse cenário no território inglês, por exemplo, durante muito tempo, somente exportou seus bens finais ou maquinários considerados obsoletos.

A exportação de capitais e tecnologia, desse modo, era voltada para os ramos de transporte, iluminação e comunicações. Setores subsidiários ao modelo primário-exportador eram estimulados com o intuito de otimizar o desempenho da estrutura produtiva vigente no território nacional e regional, perpetuando o papel periférico do país na divisão internacional do trabalho. Este padrão de relação econômica atendia aos interesses da elite ligada ao setor agrícola doméstico, principalmente cafeeiro e açucareiro.

Os avanços tecnológicos nas áreas de transporte, iluminação pública e comunicações representavam processos modernizadores, mas não produziam o efeito de transformação do modelo monocultor de viés exportacionista brasileiro. Na verdade, reforçavam o caráter desse modelo presente na economia brasileira como um todo. Constituindo-se, desse modo em uma experiência modernizadora e conservadora ao mesmo tempo. Graham (1973, p. 33) ressaltou 0 padrão de investimentos estrangeiros no país:

Em 1866, das 69 empresas estrangeiras e brasileiras, excluindo-se os bancos que tinham vida funcional, apenas três eram fabris: um curtume, uma fábrica de tecidos e outra de sabão e velas. 0 que existia em maior número eram 27 empresas de transporte (fluvial, marítimo, linhas férreas e estradas de rodagem), 22 companhias de seguros, 13 companhias de serviços públicos e 4 de mineração.

As estreitas relações econômicas entre o Brasil e a Inglaterra ao longo do século XIX evidenciavam a expressiva supremacia dos produtos industrializados britânicos no cotidiano da vida no país. Freyre (1948, p. 90) retratou muito bem esse quadro:

É quase impossível ao brasileiro ouvir falar em máquina, em motor, em ferramenta, em estrada de ferro, em rebocador, em draga, em cabo submarino, em telégrafo, em artigos de aço e ferro, em brinquedo mecânico, em cadeira de mola, em louça doméstica, em 
bicicleta, em patim, em aparelho sanitário, em navio de guerra, em vapor, em lancha, em fogão a gás ou a carvão, sem pensar em ingleses.

A presença britânica era tão expressiva que um ministro norte-americano assim se referiu a esse cenário: "A Grã-Bretanha fornece ao Brasil os seus navios a vapor e a vela, calça-lhe e drenaIhe as ruas, ilumina-lhe a gás as cidades, constrói-lhe as ferrovias, explora-lhe as minas, é o seu banqueiro [...] veste e faz tudo, menos alimentar o povo brasileiro"(RODRIGUES, 1953, p.80). A participação inglesa tão importante no cenário brasileiro no decurso do oitocentos, apresentou 0 mesmo perfil em território baiano. Analisemos o padrão dos investimentos ingleses na província da Bahia no transcurso do século XIX, destacando três casos: o setor metalúrgico, a iluminação pública por meio da Bahia Gas Company Limited e a Companhia Bahiana de Navegação a Vapor.

\section{Padrão dos investimentos britânicos na Bahia oitocentista}

A análise da economia baiana no transcurso do século XIX evidencia o mesmo padrão de investimentos britânicos observado no quadro nacional, com a maior parte dos capitais direcionados aos setores subsidiários ao centro dinâmico da estrutura produtiva interna - 0 açúcar. Embora em decadência, principalmente a partir da segunda metade do período oitocentista, a atividade açucareira ainda representava o setor mais importante do quadro doméstico, como atesta a tabela abaixo:

Tabela 1.

Participação dos principais produtos na pauta de exportações da Bahia, 1850-1880

\begin{tabular}{c|c|c|c|c|c|c|c}
\hline Anos & Açúcar (\%) & $\begin{array}{c}\text { Fumo } \\
(\%)\end{array}$ & $\begin{array}{c}\text { Cacau } \\
(\%)\end{array}$ & $\begin{array}{c}\text { Café } \\
(\%)\end{array}$ & $\begin{array}{c}\text { Algodão } \\
(\%)\end{array}$ & $\begin{array}{c}\text { Diamante } \\
(\%)\end{array}$ & $\begin{array}{c}\text { Outros } \\
(\%)\end{array}$ \\
\hline 1850 & 69,8 & 12,6 & 0,5 & 4,6 & 3,3 & 3,6 & 5,6 \\
\hline 1855 & 49,4 & 12,7 & 0,9 & 8,0 & 2,0 & 15,2 & 11,8 \\
\hline 1860 & 32,0 & 18,3 & 2,4 & 12,0 & 0,1 & 15,0 & 20,2 \\
\hline 1865 & 36,5 & 20,4 & 1,1 & 9,0 & 20,0 & 7,2 & 5,8 \\
\hline 1870 & 38,8 & 28,6 & 2,0 & 5,6 & 9,2 & 5,1 & 10,7 \\
\hline 1875 & 20,4 & 40,7 & 2,4 & 23,3 & 0,3 & 2,8 & 10,1 \\
\hline 1880 & 42,3 & 22,4 & 5,6 & 15,4 & - & - & - \\
\hline
\end{tabular}

Fonte: TAVARES, PURIFICAÇÃO, 1978, p. 24. Tabela adaptada pelo autor.

Há uma notória queda na participação do açúcar no total das exportações da Bahia no decorrer da segunda metade do século XIX, apesar de uma recuperação momentânea na década de 1880. Como pode ser constatado na tabela 1, em 1850 a economia açucareira atendia por aproximadamente $70 \%$ do total exportado pela província, número que caiu ao patamar de $20,4 \%$ no 
ano de 1875, nesse caso, agravado pela moléstia da cana que afetou sobremaneira a produção regional. De qualquer modo, o percentual de 42,3\% registrado em 1880, confirma a perda de importância gradual de um produto que foi hegemônico no cenário baiano por muito tempo, mas também evidencia que ainda era sua principal mercadoria exportada.

A presença dos capitais britânicos se acentuou após o fim do tráfico de escravos em 1850, período que refletiu uma mudança no padrão interno de inversão de capitais, antes alocados prioritariamente no intercâmbio de cativos, mas que se transmudam em investimentos nos setores de caráter mais urbano ou no desenvolvimento de algum ramo industrial, ainda que rudimentar. Uma evidência desse processo pode ser observada na análise do segmento metalúrgico, inaugurado na província da Bahia em 1850 por ingleses que fundaram a John Helling e Cia., empresa de fundição e maquinaria que estava notadamente direcionada para auxiliar a navegação a vapor, as primeiras estradas de ferro e os engenhos de açúcar que passavam por um processo lento de modernização 3 .

0 estudo mostra que das cinco primeiras empresas metalúrgicas na Bahia, quatro eram inglesas e ao longo do século XIX, de um total de 15 empresas que atuaram neste setor, 8 foram constituídas por capitais britânicos, o que representa 53,33\% da participação final (SAMPAIO, PEDRÃO, 2002, p. 51). A pesquisa contribuiu no sentido de reforçar o argumento dos investimentos em setores subsidiários ao centro dinâmico da economia baiana oitocentista. 0 crescimento do setor metalúrgico baiano estava voltado para atender às necessidades urbanas mais básicas e tradicionais, tais como confecção de grades, bancos, dobradiças, assim como para a produção de peças destinadas aos transportes, que experimentavam um momento de modernização com 0 advento das máquinas a vapor, fruto do pioneirismo inglês e, conforme mencionado, para os engenhos de açúcar.

Os serviços públicos urbanos também atravessaram um momento de modernização no período pós-tráfico de escravos. A diversificação dos investimentos originários dos capitais ociosos, voltou-se para o processo de urbanização, destacadamente na cidade de Salvador, capital da província. A expansão dos setores do comércio e serviços foi bastante expressiva com ampliação do número de estabelecimentos bancários, empresas de seguros, companhias de transportes urbanos e empresas de iluminação pública como a Bahia Gas Company Limited.

Empresa fundada com capitais ingleses, a Companhia do Gaz da Bahia inaugurou um processo de modernização no serviço da iluminação pública na província da Bahia. Fruto do

\footnotetext{
3 Para saber mais: SAMPAIO, Marcos Guedes Vaz, PEDRÃO, Fernando Cardoso. Formação de um setor metalúrgico na província da Bahia oitocentista: a presença britânica. Salvador: Revista de Desenvolvimento Econômico/UNIFACS, ano IV, n. 7, dezembro de 2002, p. 46-53.
} 
direcionamento dos investimentos britânicos para economias periféricas, no sentido de ampliar 0 escopo de atuação dos seus capitais ociosos, bem como interessados na exportação do carvão de pedra, combustível gerador do gás utilizado pelo sistema, a Inglaterra investiu na disseminação desse serviço, alcançando cidades importantes como Salvador e Rio de Janeiro.

O novo sistema de iluminação pública da capital da província da Bahia substituiu o modelo anterior, baseado na alimentação dos combustores por azeite ou querosene, pelo uso do gás à base de hidrogênio bicarbonado (SAMPAIO, 2006, p. 372). A modernização do sistema de iluminação pública permitiu prolongar as horas úteis do dia, tanto para o trabalho quanto para atividades de lazer, como lembrou Elisabeth Von der Weid (2003, p. 65). Somente para se ter uma ideia da melhoria na qualidade do sistema, pelo modelo antigo a intensidade da luz equivalia a duas velas; por meio do novo sistema essa intensidade se ampliou cinco vezes, alcançando ao equivalente à iluminação de dez velas ${ }^{4}$.

O escritório central da empresa era sediado em Londres e não existiam brasileiros ocupando posição de destaque dentro da companhia. Os principais postos, como o de superintendente, engenheiro, agente financeiro e agente comercial, por exemplo, eram ocupados por ingleses (SAMPAIO, 2006, p. 379). Os brasileiros limitavam-se às funções manuais ou técnicas de menor qualificação. A companhia permaneceu como empresa britânica até 0 ano de 1894 quando foi adquirida pelo governo do estado da Bahia que transferiu sua administração para a prefeitura da cidade de Salvador (SAMPAIO, 2006, p. 380). Este caso evidencia a alocação de capitais ociosos da economia inglesa no serviço público baiano, dentro de uma estratégia maior de ampliação e diversificação dos investimentos britânicos, contribuindo para recrudescer o fluxo de recursos para a Inglaterra, seja por meio da remessa de lucros ou pela exportação de carvão, equipamentos e matérias-primas.

Outro caso interessante que reflete o padrão dos investimentos britânicos na economia baiana oitocentista é 0 setor da navegação a vapor ${ }^{5}$. Apesar do pioneirismo norte-americano na navegação a vapor, foram os ingleses que a aperfeiçoaram disseminando seu uso. A hegemonia britânica no século XIX se consolidou com a construção naval, notadamente, de navios a vapor. Em 1870, a Inglaterra dispunha de 1.202 .000 toneladas de navios a vapor, enquanto os Estados Unidos possuíam 192.000 toneladas e a França 154.000 (CAMINHA, 1980, p. 94). Nos dizeres de

\footnotetext{
${ }^{4} O$ tipo de vela que servia de referência, segundo a pesquisa que realizei, era o de 120 grãos de espermacete, que se tratava de uma substância gorda, sólida e branca extraída do cérebro de vários cetáceos, principalmente cachalotes (SAMPAIO, 2006, p. 372).

${ }^{5}$ Desenvolvi minha tese de doutorado sobre a Companhia Bahiana de Navegação a Vapor que reforça o argumento da modernização conservadora na análise do padrão de investimentos britânicos na economia brasileira e baiana especificamente. Neste artigo me limito a uma análise pontual deste estudo, em virtude do substancial volume de informações presentes no corpo da tese que inviabiliza sua transcrição no espaço de um artigo.
} 
Hobsbawm (1978, p. 165/166): "O principal desses setores era o de construção naval, a última e uma das mais triunfantes assertivas da supremacia britânica".

Diante desse quadro, era natural que uma parte expressiva das inversões inglesas na província da Bahia se direcionasse para a modernização da navegação em águas baianas. Ramo da atividade econômica fortemente relacionado à otimização do desempenho do setor produtivo por meio da melhoria na eficiência e celeridade nos intercâmbios mercantis, bem como na sua ampliação, o panorama dos transportes na província foi amplamente beneficiado com a incorporação da tecnologia inglesa.

Como já mencionado, a presença inglesa na economia brasileira e, em particular, na economia baiana, foi bastante expressiva, estendendo-se a vários setores, dentre eles o de transportes, onde a maioria das companhias foi constituída com capitais ingleses. Segundo Castro (1978, p. 32), entre 1860 e 1875, as firmas britânicas representaram aproximadamente $94 \%$ de todo o capital externo investido no Brasil. No caso da navegação a vapor na província da Bahia, embora os ingleses tenham fundado a primeira companhia, essa mudou de mãos ao longo do período oitocentista, alternando momentos em que foi administrada por brasileiros e por britânicos.

O período áureo vivenciado pela Companhia Bahiana, contudo, ocorreu quando era administrada pelos ingleses. Houve expansão da frota, dos serviços prestados por meio de novas linhas, novos locais atendidos, inclusive estendendo para o rio São Francisco e a província de Alagoas $^{6}$. A dependência em relação à Inglaterra no que se referia a mão-de-obra técnica qualificada, matérias-primas e equipamentos era uma característica evidente.

As embarcações a vapor eram produzidas na Inglaterra e, mesmo para reparos pequenos, necessitava de peças e equipamentos de origem inglesa. Isto representava um bom negócio para diversos segmentos da economia britânica, desde o setor minerador que exportava o carvão, até 0 ramo metalúrgico, a indústria naval, bem como o mercado de trabalho que oferecia oportunidades para os técnicos em terras brasileiras e baianas. Para o desenvolvimento da economia local, esses investimentos contribuíam para melhorar a infra-estrutura de apoio aos seus principais setores, otimizando o desempenho da esfera produtiva regional, reforçando, com isso, o modelo primárioexportador, consolidando o papel desempenhado pela província da Bahia e, em especial, a economia brasileira, no processo da divisão internacional do trabalho.

Os pontos atendidos pelos vapores da Companhia Bahiana normalmente serviam como entreposto comercial da produção agrícola, extrativa e pecuária, que seguia por vias terrestres

\footnotetext{
6 Ver: SAMPAIO, Marcos Guedes Vaz. Uma contribuição à história dos transportes no Brasil: a companhia bahiana de navegação a vapor (1839-1894). 2006. 370 p. Tese (Doutorado em História Econômica) - Faculdade de Filosofia, Letras e Ciências Humanas, Universidade de São Paulo, 2006.
} 
precárias para embarcar nos navios com destino aos mercados compradores regionais ou ao porto de Salvador para seguir em embarcações inglesas para a Europa. Desse modo, tornava os intercâmbios mercantis mais eficientes, por meio da maior regularidade e rapidez, permitindo incrementar o volume transacionado, ampliando a receita dos produtores e dos comerciantes.

0 desempenho melhor da atividade econômica primária por meio desse processo de modernização subsidiário, estimulava novos investimentos neste setor, bem como os discursos em defesa do modelo primário-exportador, tal como demonstrou Nícia Villela Luz (1961). Esse quadro contribuiu para reforçar o padrão da estrutura produtiva interna, em detrimento de uma política direcionada para a industrialização do país, mantendo sua inserção periférica no cenário econômico mundial e um organismo social, econômico e político nacional identificado com as hostes do arcaísmo de uma sociedade assentada na agricultura, de base rural e distante de promover uma transformação burguesa, urbana e industrial que veio a ocorrer tardiamente no Brasil.

\section{Considerações finais}

A Inglaterra ocupou o papel de nação hegemônica do cenário mundial no transcurso do século XIX, situação que já se delineava desde a centúria anterior, mas que se consolidou com 0 advento da era industrial. O recrudescimento da economia britânica sob o primado da industrialização permitiu uma expressiva amplificação de sua rede de influências sobre outras nações. Este processo se verificou na expansão dos seus domínios coloniais e no redimensionamento espacial de seus investimentos, onde países periféricos no panorama internacional se tornaram destino importante dos capitais ingleses.

O Brasil estava entre as economias que receberam volume substancial das inversões britânicas, cuja participação foi a mais expressiva no total dos investimentos externos no âmbito da estrutura produtiva nacional. As principais inovações tecnológicas e o processo de modernização experimentado pela economia brasileira no decurso do período oitocentista são oriundos da presença inglesa.

Diversos pesquisadores ${ }^{7}$ que se debruçaram sobre a análise das relações econômicas entre o Brasil e a Inglaterra dentro do século XIX observaram certo padrão nos investimentos ingleses, notadamente direcionados ao setor de serviços, por meio das companhias de iluminação pública, seguros, bancos e transportes. As inversões nestes ramos da atividade econômica refletem uma estratégia que privilegia a diversificação das aplicações do capital, porém em segmentos subsidiários ao principal setor da atividade econômica nativa, a agricultura de viés exportacionista.

\footnotetext{
7 Ver: GRAHAM, 1973; MANCHESTER, 1973; FURTADO, 1979; DOWBOR, 1982; PRADO JR., 1986; MELLO, 1991.
} 
Este padrão dos investimentos ingleses no território brasileiro permite interpretar que existia um projeto de modernização da infra-estrutura de apoio ao centro dinâmico da atividade econômica nacional, porém sem contribuir para transformar o modelo vigente. Esse projeto atendia aos interesses dos capitalistas britânicos, ansiosos por expandir sua esfera de influência econômica ao redor do mundo, bem como amplificar a distribuição espacial dos seus investimentos, contudo, sem interferir nos interesses das elites domésticas, fortemente relacionadas à agricultura monocultora de exportação e ao setor comercial.

Na verdade, a organização estrutural dessa estratégia atendia aos interesses de ambos, uma vez que, a particularidade dos investimentos ingleses no Brasil, contribuía para melhorar o setor subsidiário ao segmento exportador, tornando mais eficientes as comunicações em geral e os transportes em particular, proporcionando redução de custos e ganhos de escala para os empreendimentos produtivos das elites nativas. Tornava-se, desse modo, um exemplo interessante do que se convencionou chamar de modernização conservadora, dado que promove a modernização do sistema de apoio, enquanto conserva, ou até mesmo reforça o grande modelo primário-exportador vigente.

Quando se realiza um recorte territorial e procura analisar o caso específico da província da Bahia dentro deste quadro mais amplo, o padrão de investimentos se repete. Mesmo em segmentos produtivos da atividade econômica, como no caso da metalurgia, os investimentos são direcionados para fabricação de utensílios para uso cotidiano da população ou para reforçar o centro dinâmico da economia interna, a cultura açucareira, tanto na fabricação de peças para os engenhos, quanto no auxílio à navegação a vapor ou às ferrovias.

A análise do serviço da iluminação pública e da Companhia Bahiana de Navegação a Vapor corroboram essa interpretação a respeito do padrão de investimentos ingleses. Como argumentou Castro (1978), tratava-se de uma preocupação da Inglaterra em manter e até reforçar o processo de divisão internacional do trabalho, onde ela se especializaria na produção e comercialização de bens industriais, enquanto as nações periféricas perpetuariam seu papel de exportadoras de bens primários e matérias-primas para alimentar as indústrias e as sociedades das economias centrais.

\section{Referências Bibliográficas}

1. AMIN, S. O desenvolvimento desigual - ensaio sobre as formações sociais do capitalismo periférico. Rio de Janeiro: Forense Universitária, 1976.

2. CAMINHA, J. C. G. História Marítima. Rio de Janeiro: Biblioteca do Exército, 1980.

3. CARDOSO, F. H., FALETTO, E. Dependência e desenvolvimento na América Latina: ensaio de interpretação sociológica. 6 ed., Rio de Janeiro: Zahar, 1981.

4. CASTRO, A. C. As Empresas Estrangeiras no Brasil (1860-1913). Rio de Janeiro: Zahar, 1978.

5. COHEN, B. J. A questão do imperialismo - a economia política da dominação e dependência. Rio de Janeiro: Zahar, 1976. 
6. DOMINGUES, J. M. A dialética da modernização conservadora e a nova história do Brasil. Dados - Revista de Ciências Sociais, Rio de Janeiro, vol. 45, n.03, 2002, p. 459-482.

7. DOWBOR, L. A formação do capitalismo dependente no Brasil. 3 ed., São Paulo: Brasiliense, 1982.

8. FERNANDES, F. Capitalismo dependente e classes sociais na América Latina. 3 ed., Rio de Janeiro: Zahar, 1981.

9. FRANK, A. G. Acumulação dependente e subdesenvolvimento: repensando a teoria da dependência. São Paulo: Brasiliense, 1980. (Trad. Cláudio Alves Marcondes).

10. FURTADO, Celso. Formação Econômica do Brasil. 16.a ed., São Paulo: Cia. Editora Nacional, 1979.

11. GRAHAM, R. Grã-Bretanha e o Início da Modernização no Brasil (1850-1914). São Paulo: Brasiliense, 1973. (Trad. Roberto Machado de Almeida).

12. HOBSBAWN, E. J. Da revolução industrial inglesa ao imperialismo. Rio de Janeiro: Forense-Universitária, 1978. (Trad. Donaldson Magalhães Garschagen).

13. HUNT, E. K. História do pensamento econômico. 11 ed., Rio de Janeiro: Campus, 1989. (Trad. José Ricardo Brandão Azevedo).

14. JAGUARIBE, H. et al. La Dependencia politico-económica de America Latina. México: Siglo XXI, 1969.

15. LUZ, N. V. A Luta Pela Industrialização do Brasil (1808-1930). São Paulo: Difusão Européia do Livro, 1961.

16. MANCHESTER, A. K. Preeminência Inglesa no Brasil. 1.a ed., São Paulo: Brasiliense, 1973. (Trad. Janaína Amado).

17. MARINI, R. M. Dialética da dependência. Petrópolis: Vozes, 2000.

18. MELLO, J. M. C. O Capitalismo Tardio. 8.a ed., São Paulo: Brasiliense, 1991.

19. MOORE JR., B. As origens sociais da ditadura e da democracia. São Paulo: Martins Fontes, 1983.

20. MYRDAL, G. Teoria econômica e regiões subdesenvolvidas. 2 ed., Rio de Janeiro: Saga, 1968. (Trad. N. Palhano).

21. OLIVEIRA, F. de. A economia da dependência imperfeita. 4 ed., Rio de Janeiro: Graal, 1984.

22. RODRIGUES, J. M. A Rivalidade Comercial de Norte-Americanos e Ingleses no Brasil do Século XIX. São Paulo: IPE/USP, Revista de História da Economia Brasileira, vol. 1, n.o 1, 1953.

23. SADER, E. S. Dialética da dependência. Petrópolis: Vozes, 2000.

24. SAMPAIO, M. G. V., PEDRÃO, F. C. Formação de um setor metalúrgico na província da Bahia oitocentista: a presença britânica. Salvador: Revista de Desenvolvimento Econômico/UNIFACS, ano IV, n. 7, dezembro de 2002. p. 46-53.

25. SAMPAIO, M. G. V. Presença britânica no serviço público da cidade de Salvador: o caso da Bahia Gas Company Limited (1861-1894). In: FERLINI, Vera Lúcia, MOURA, Esmeralda Blanco Bolsonaro (orgs.). História econômica: agricultura, indústria e populações. São Paulo: Alameda, 2006.

26. SAMPAIO, M. G. V. Uma contribuição à história dos transportes no Brasil: a companhia bahiana de navegação a vapor (1839-1894). 2006. 370 p. Tese (Doutorado em História Econômica) — Faculdade de Filosofia, Letras e Ciências Humanas, Universidade de São Paulo, 2006.

27. STEIN, S., STEIN, B. H. A herança colonial da América Latina: ensaios de dependência econômica. 4 ed., Rio de Janeiro: Paz e Terra, 1989. (Trad. José Fernandes Dias).

28. SUNKEL, O. O marco histórico do processo desenvolvimento-subdesenvolvimento. 2 ed., Rio de Janeiro: Forum, 1973. (Trad. Regina Maia).

29. SUNKEL, O. Um ensaio de interpretação do desenvolvimento latino-americano. São Paulo: Difel, 1975. (Trad. João Maia).

30. TAVARES, L. M. T., PURIFICAÇÃO, V. M. P. Cana-de-Açúcar. In: BAHIA. Secretaria de Planejamento, Ciência e Tecnologia. A Inserção da Bahia na Evolução Nacional - 1.a Etapa: 1850/1889 - Atividades Produtivas. Salvador: Fund. Centro de Pesquisas e Estudos - CPE, 1978. 